\title{
"Ninguém está falando em liberação da droga": ressignificação da maconha nos programas matinais das redes Globo e Record
}

"Nobody is talking about drug legalization": re-signification of marijuana on Globo and Record morning programs

"Nadie habla de liberación de drogas": resignificación de la marihuana en los programas matutinos Globo y Record

\section{Resumo}

O uso medicinal e terapêutico da Cannabis spp. tem uma longa história na humanidade, mas a atual Política Nacional de Drogas do Brasil ainda impõe processo burocrático para plantio, produção e consumo da substância para fins medicinais. Esse artigo tem o objetivo de analisar e comparar como programas de entretenimento matinais das redes Globo e Record abordaram o uso medicinal dos derivados da maconha no Brasil entre 2014 e 2018, nas quais são destaques os movimentos sociais a favor da liberação da maconha medicinal para famílias de pacientes que não respondem aos tratamentos convencionais. Observou-se mudança significativa na abordagem, no que tange à seleção lexical, das emissoras durante o processo de liberação da importação. A segunda modificação observada consiste na escolha das fontes para as entrevistas. Se num primeiro momento tem-se forte representação das famílias, construindo uma imagem familiar do uso da substância, com o passar do tempo essas são substituídas por médicos e neurocientistas.

Palavras-chave: Mediações; Mídia televisiva; Cannabis medicinal.

\begin{abstract}
The medicinal and therapeutic use of Cannabis spp. has a long history in humanity, but the current National Drug Policy in Brazil still imposes a bureaucratic process for planting, producing and consuming the substance for medicinal purposes. This article aims to analyze and compare how morning entertainment programs from Globo and Record networks approached the medicinal use of cannabis derivatives in Brazil between 2014 and 2018, in which the social movements in favor of the release of medical marijuana for families of patients who do not respond to conventional treatments are highlighted. There was a significant change in the approach, with regard to lexical selection, of the broadcasters during the import clearance process. The second modification observed is the choice of sources for the interviews. If at first there is a strong representation of families, building a familiar image of substance use, over time they are replaced by doctors and neuroscientists.
\end{abstract}

Keywords: Mediations; Television media; Medical cannabis.

\section{Resumen}

El uso medicinal y terapéutico de Cannabis spp. tiene una larga historia en la humanidad, pero la actual Política Nacional de Drogas en Brasil aún impone un proceso burocrático para plantar, producir y consumir la sustancia con fines medicinales. Este artículo tiene como objetivo analizar y comparar cómo los programas de entretenimiento matutino de las redes Globo y Record abordaron el uso medicinal de los derivados del cannabis en Brasil entre 2014 y 2018, en los que se destacan los movimientos sociales a favor de la liberación de marihuana medicinal para familias de pacientes que no responden a los tratamientos convencionales. Hubo un cambio significativo en el enfoque, con respecto a la selección léxica, de los organismos de radiodifusión durante el proceso de despacho de importación. La 
segunda modificación observada es la elección de fuentes para las entrevistas. Si al principio hay una fuerte representación de las familias, construyendo una imagen familiar del uso de sustancias, con el tiempo son reemplazadas por médicos y neurocientíficos.

Palabras clave: Mediaciones; Medios de television; Cannabis medicinal.

\section{Introdução}

Desde 2014, o uso medicinal da Cannabis sativa no Brasil tem sido debatido em várias esferas da sociedade. Pesquisas diversas comprovam os benefícios de seus derivados - principalmente o canabidiol (CBD) e o tetraidrocanabinol (TCH) - no tratamento de epilepsia, autismo, Parkinson, Alzheimer, entre outros (Carlini, Karniol, Renault \& Schuster, 1974; Garcia, Cruz, Silva, Cardoso \& Arruda, 2020; Carvalho, et al., 2020; Barbosa, Barros, Lima, Silva, \& Souza, 2020; Silva, et al., 2020). Apesar dos resultados desses estudos, a política de drogas nacional vigente é composta pela Lei de Drogas no Brasil (Lei $n^{\circ}$ 11.343/2006) e pelo Sistema Antidrogas instituído pelo Decreto n5.912/2006. Essa política proíbe o uso da maconha e de seus derivados como substâncias proibidas, assim como o plantio, a cultura, a colheita e a exploração. Isso pode dificultar ou até impedir o acesso aos compostos, além de retardar o avanço de pesquisas sobre o tema.

Seguindo o exemplo de países como Canadá, Estados Unidos, Colômbia e Uruguai, que recentemente vêm aprovando leis que permitem o uso de derivados da maconha para fins medicinais e recreativos (Instituto Igarapé, 2019), no Brasil, grupos sociais têm pressionado o Estado para avançar neste debate. Depois da mobilização de diversos setores sociais, medicinais e empresariais e das famílias, a Agência Nacional de Vigilância Sanitária (Anvisa) regulamentou a importação do canabidiol em janeiro de 2015 e a produção e comercialização de medicamentos à base da planta em 2019 após as consultas públicas 654 e 655 (Rodrigues, Mourão \& Lopes, 2020).

É ilustrativo neste caso o papel da mídia para dar visibilidade ao tema, principalmente a partir da divulgação no Fantástico do documentário Ilegal (2014), produzido por Tarso Araújo e Raphael Erichsen, que mostra a rotina e sofrimento do tratamento de Anny Fischer, na época com quatro anos de idade, e a luta de sua família pela liberação da importação do canabidiol (Oliveira, 2016). A criança sofre de uma síndrome rara marcada por crises epilépticas intensas e frequentes. Após o uso do CBD, as crises diárias diminuíram consideravelmente, melhorando a qualidade de vida da menina e de sua família. Anny se tornou inspiração para diversas outras famílias que passavam por dificuldades e situações semelhantes. Em abril de 2014, os pais de Anny conseguiram a autorização da Anvisa para importar o medicamento, o que demonstra o papel da mediação cultural das mídias no processo de formação de opinião da sociedade brasileira e, mais especificamente, no modo como o público interpreta e enquadra pesquisas científicas (Oliveira, 2016).

O caso de Anny Fischer ilustra os resultados da quarta edição da pesquisa Percepção Pública da Ciência e Tecnologia no Brasil (2015) sobre a principal fonte de popularização da Ciência e Tecnologia para os brasileiros ser a televisão, seguida da internet. Ressaltamos que a mobilização da família Fischer não se restringiu à TV, mas de fato aliava TV e internet, tanto pela divulgação do documentário na Netflix, quanto em grupos nas redes sociais digitais como Facebook (Oliveira, 2016).

A mediação é um conceito complexo dentro dos estudos de comunicação. Segundo Bastos (2012, p.53, Grifos do autor), "Medium, media, mediação e midiatização são estratos conceituais que se referem a um mesmo conjunto de fenômenos". Partindo desse princípio, o autor busca trazer os diversos sentidos para o termo mediação que envolvem: intervenção, negociação, intermediação, reconciliação, enfim aquele que está entre ou no meio ligando duas coisas, pessoas ou contextos. A Teoria da Mediação Social de Martín Serrano busca estudar a produção, transmissão e uso da cultura, com base na análise de modelos culturais e suas funções. Para esse autor, os meios de comunicação de massa, incluindo jornais, revistas, rádio e televisão, participam do processo de representação do mundo, ao passo que selecionam determinados eventos e os tornam públicos, atuando como instituições mediadoras (Serrano, 1993).

Pensando no papel mediador da mídia de levar a informação ao público, é possível compreender o resultado obtido 
pela Empresa Jr. de Consultoria Pública Strategos (2016) sobre a influência da cobertura midiática para a sensibilização dos deputados e da população brasileira sobre o uso do Canabidiol. Outro critério que deve ser considerado são os interesses por trás das narrativas jornalísticas. Conforme Motta (2013), há pelo menos três vozes em disputa nessas narrativas: o veículo, o jornalista e a personagem (fontes entrevistadas). No caso da cobertura sobre o canabidiol, Oliveira (2016) afirma que a reclassificação do Canabidiol foi possível pala associação de uma rede "visível" - daqueles que estavam à frente das negociações - cujos interessados chegaram a um ponto comum de diálogo. Essa rede era formada pela própria família Fischer, o jornalista e documentarista Tarso Araújo (responsável inserção do caso da família na mídia por meio do documentário Ilegal) e a imprensa. Essa mesma rede também apresentava uma vertente de que abarca a produção do conhecimento sobre os usos seguros do Canabidiol, envolvendo Alexandre Crippa (médico que assinou o laudo de Anny Fischer para uso do medicamento à base da Cannabis), a Anvisa e o Conselho Federal de Medicina.

Com base nas matérias examinadas para este artigo, acredita-se que, para além dos atores envolvidos que receberam destaque na mídia, a escolha de fontes entrevistadas assim como a seleção lexical ao retratar o tema contribuíram para o processo de ressignificação do Canabidiol, visto que outras famílias e profissionais da saúde e do direito tiveram a oportunidade de externar suas necessidades, experiências e demandas e opiniões. Neste contexto, questiona-se: "A partir de que estratégias as redes de televisão Globo e Record ressignificaram o debate sobre o uso medicinal do canabidiol?". Para responder à essa questão-problema de pesquisa, este estudo tem o objetivo de analisar e comparar como programas de entretenimento matinais das redes Globo e Record abordaram o uso medicinal dos derivados da maconha no Brasil entre 2014 e 2018. Para tal fim, foram coletadas matérias que faziam menção ao tema veiculadas pelos programas Encontro com Fátima Bernardes e Bem Estar, ambos na plataforma online Globoplay, e Hoje em Dia, no site R7. Após a seleção das matérias, realizou-se a Análise de Conteúdo, com base em Bardin (2016).

\section{Metodologia}

A narrativa jornalística é responsável por criar a história do presente. Porém, as matérias são apresentadas de forma segmentada e, para analisar o acontecimento como um todo, faz-se necessário reordenar temporalmente a cronologia do enredo, identificar os conflitos, posicionar as personagens, o clímax e o desfecho do acontecimento intriga. A recomposição das matérias geraria um novo produto que vai além narratividade da representação realista e difusa do real, se tornando uma atividade produtora de sentidos culturais (Motta, 2013). Neste caso, o público ou audiência pode construir coletivamente significados a partir das informações obtidas na matéria e tomar decisões a respeito das informações considerando seu contexto, suas próprias experiências, memórias e cultura.

Retomando o objetivo de realizar a mediação do meio de comunicação televisão no processo de ressignificação do canabidiol de uma substância ilegal a um medicamento autorizado pela Anvisa, e na impossibilidade de analisar todas as matérias publicadas e/ou veiculadas sobre o tema, optou-se por selecionar os três programas: Encontro com Fátima Bernardes, Bem Estar e Hoje em Dia. Após a seleção, os vídeos foram transcritos, de forma que a análise se limita ao discurso oral dos apresentadores, repórteres e personagens. É preciso reconhecer que essa metodologia não explora todo o potencial do conteúdo audiovisual, mas é uma forma de compreender a narrativa, o posicionamento dos envolvidos e a ressignificação do tema ao longo do tempo.

Para análise, utilizou-se a metodologia de Análise de Conteúdo (Bardin, 2016), que possibilita observar diversas mensagens emitidas nos distintos códigos e suportes de discurso. O discurso jornalístico televisivo é uma comunicação de massa que se enquadra dentro do discurso oral. Segundo Bardin (2016), o método se organiza da seguinte forma: (1) análise; (2) exploração do material; (3) e tratamento dos resultados, inferência e interpretação. A primeira fase busca escolher os documentos a serem analisados, formular hipóteses e objetivos, elaborar os indicadores que fundamentam a interpretação final. 
A exploração do material é a fase de análise propriamente dita e, por fim, faz-se o tratamento dos resultados obtidos e interpretação, momento da transformação dos resultados brutos em dados significativos e válidos. Vale destacar que, apesar da Análise de Conteúdo realizar, por vezes, a contabilização dos dados, esta metodologia faz um estudo qualitativo do objeto pesquisado. Deste modo, os dados aqui levantados são representativos devido a interpretação do pesquisador, não correspondendo necessariamente a nenhuma amostra estatística da população como um todo (Pereira, Shitsuka, Parreira \& Shitsuka, 2018).

Durante coleta de dados, buscou-se o termo "canabidiol" nas plataformas Globoplay e R7. Em seguida, filtrou-se, dentre todo conteúdo obtido, apenas as matérias veiculadas nos três programas matinais selecionados para análise e comparação. Optou-se por esses três veículos, por apresentarem um formato semelhante em redes de televisão concorrentes, a fim de observar como cada uma se posiciona diante do mesmo tema. Assim, foi possível descrever, mesmo que parcialmente, a situação comunicativa do debate sobre a liberação e uso do canabidiol na televisão brasileira. Destaca-se que, em 2015, o formato do programa Hoje em Dia sofreu uma reformulação, deixando de ter as características semelhantes aos programas de entretenimento matinais da Globo e recebendo uma "roupagem jornalística". Por essa razão, a análise comparativa desse programa ocorre somente em 2014 e 2015.

\section{Resultados e Discussão}

A página do Hoje em Dia, na plataforma R7 (2019) da Record, descreve que esse é um programa que busca mesclar matérias, prestação de serviços e entretenimento, tendo como compromisso: "informar e formar a opinião pública, sem perder de vista a opção de lazer que muitos brasileiros buscam na telinha”. Em 2019, contava com a apresentação Ana Hickmann, Cesar Filho, Renata Alves e Ticiane Pinheiro, mas vários outros já passaram pelo programa ao longo dos seus quase 15 anos. Os temas abordados são diversificados e englobam desde práticas culinárias, moda e artes, até fatos e flagrantes do cenário nacional e internacional, passando por dicas e orientações sobre saúde, economia doméstica, direito, cidadania, paisagismo, decoração, entre outros. Há também interação e participação do telespectador por meio de telefone, internet ou pelos microfones dos repórteres. A atração vai ao ar de segunda a sexta-feira, entre 9h50 e 11h40 pelo horário de Brasília.

Em relação ao Bem Estar, Carvalho et al. $(2015$, p.7) descrevem que o programa busca "tratar de assuntos da saúde e, frequentemente, mencionar pesquisas científicas, termos técnicos e suas explicações, animações que exemplificam o funcionamento do corpo humano e até, em menor escala, trazer cientistas para discutir alguns desses temas de saúde”. Era transmitido pela Globo de segunda a sexta-feira, antecedendo o Encontro com Fátima Bernardes, entretanto, o programa teve sua última edição em 5 de abril de 2019, se tornando um quadro esporádico dentro da programação do Encontro.

O Encontro com Fátima Bernardes se diferencia dos demais analisados por ter um formato de programa de auditório, mas, assim como o Bem Estar e o Hoje em Dia, busca abordar a informação de forma descontraída. Apresentado desde a primeira edição em 2012 pela jornalista Fátima Bernardes, sua proposta é discutir "temas do cotidiano, sob a forma de batepapo com convidados", mas também apresenta matérias jornalísticas gravadas ou ao vivo, brincadeiras e apresentações musicais (Stürmer, 2014). O programa é transmitido ao vivo de segunda a sexta-feira entre $10 \mathrm{~h} 30$ e meio dia no horário de Brasília.

Tendo a liberação da importação do CBD pela Anvisa ocorrido no dia 14 de janeiro de 2015, foram analisadas seis matérias anteriores a essa data e oito posteriores à regulamentação. Como a matéria da reunião da Anvisa que autorizava a importação ocorreu no período da tarde, foi veiculada apenas na manhã seguinte pelo Bem Estar. Vale ressaltar que o programa que mais se dedicou a discutir o tema foi o Bem Estar, tendo tratado do assunto em seis matérias entre 2014 e 2018.

O primeiro aspecto das matérias que demonstra a ressignificação são os títulos, pois há uma progressão desde a explicação dos benefícios do canabidiol, ou derivado da maconha, até o desuso desses termos. Neste sentido, a sequência 
organizada das matérias parece confirmar o pensamento de Motta (2013) e criar um novo produto, ou uma grande narrativa, mesmo sendo oriundas de programas e emissoras distintas. Veja a linha do tempo a seguir (Figura 1):

Figura 1 - Títulos das matérias organizados cronologicamente.

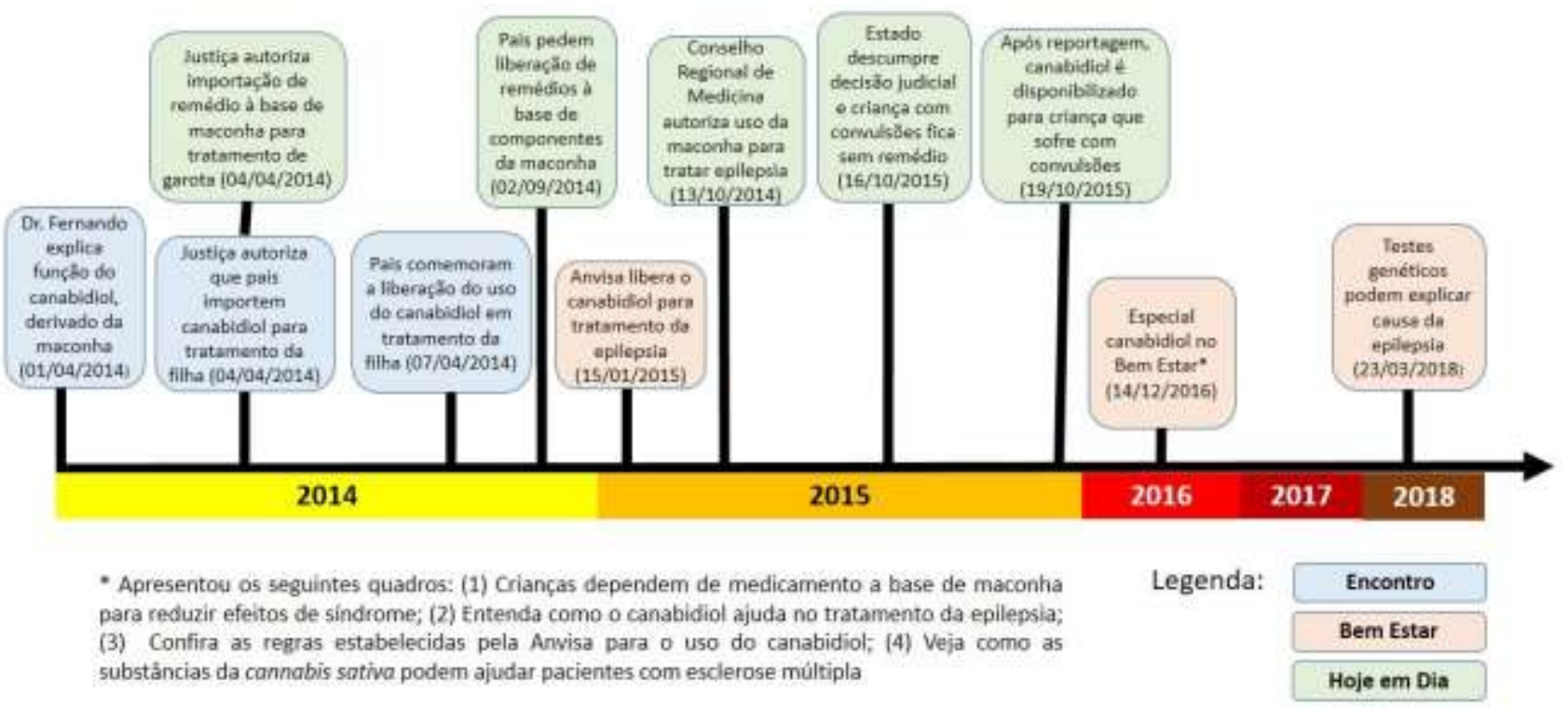

Fonte: Dados da pesquisa.

Ao organizar as matérias de forma cronológica (Figura 1), é possível observar como os programas se posicionam diante do tema ao longo do tempo. O Encontro foi o primeiro a abordar o assunto, mas se limitou a acompanhar o caso de Anny Fischer, não tratando mais da questão após a entrevista com os pais da menina. A partir desse ponto, a discussão na Globo passa a retratar o processo de liberação da importação e suas regras, assim como o uso do canabidiol no tratamento da epilepsia. Ao deixar de ser um assunto familiar para se tornar uma questão de saúde pública e cidadania, os temas se assemelham ao perfil do programa Bem Estar, que pertence ao gênero de jornalismo utilitário, o qual se propõe orientar, aconselhar e servir de guia para o cidadão em situações do cotidiano. Vale ressaltar que, em 2016, o Bem Estar dedicou uma edição completa a cannabis medicinal, apresentou três reportagens além da participação de profissionais para responder questões do público e trazer informações científicas sobre o tema.

A primeira matéria da Record coincide temporalmente com a segunda da Globo, devido à importância da liberação de importação do canabidiol na justiça para a família Fischer. Entretanto, enquanto a Globo utilizou o termo Canabidiol, a Record escolheu "remédio à base de maconha", frisando diversas vezes ao longo da matéria ser contra a legalização da maconha, mas defender o uso medicinal da substância. O canabidiol permanece presente nos títulos das reportagens em 2015 e 2016. Após um hiato em 2017, quando não houve reportagens, no ano de 2018, a única matéria que tratou do tema nos programas de entretenimentos matinais o trouxe apenas como forma de tratamento para a epilepsia, sem destaque no título.

Além da progressão do debate, as matérias de ambas emissoras procuram construir a informação científica ao mesmo tempo que informam as novidades sobre o processo de liberação da substância pelos órgãos responsáveis (Conselho Regional de Medicina e Anvisa). Considerando-se que após 2015 houve pouco avanço no processo de liberação, o tratamento de doenças com o canabidiol se torna o assunto principal. As doenças citadas pelos programas foram listadas e as referências a elas contabilizadas na Tabela 1. 
Tabela 1 - Número de citações das doenças que podem ser tratadas com uso do canabidiol.

\begin{tabular}{cccccccc} 
& & Epilepsia & Alzheimer & Parkinson & Esclerose Múltipla & Autismo & AIDS \\
\hline Record & Hoje em Dia & 11 & 0 & 0 & 0 & 1 & 0 \\
Globo & Encontro & 4 & 1 & 1 & 1 & 0 & 1 \\
& Bem Estar & 28 & 0 & 0 & 2 & 0 & 0 \\
\hline
\end{tabular}

Fonte: Dados da pesquisa.

Conforme a tabela 1, a epilepsia é o quadro químico mais citado nas matérias. Nas matérias, são tidas como causa da epilepsia as síndromes de West, de Dravet e de Schinzel Giedion. Esses distúrbios neurodegenerativos são mais comuns em crianças ou adolescentes e levam o paciente a sofrer até 80 crises convulsivas diárias. Por essa razão, a família aparece com frequência nesses textos, a fim de comprovar a credibilidade do canabidiol, garantindo a melhora significativa na qualidade de vida de seus filhos e afirmando que o medicamento é uma esperança para o tratamento de casos semelhantes.

Os passos seguintes da análise buscam comparar as matérias da Globo e da Record. Devido ao fato da ausência de matérias na Record após 2015, só foram consideradas nesta parte do estudo as matérias veiculadas nos anos de 2014 e 2015. Para observar conceitos-chave, utilizou-se a ferramenta de contagem de palavras WordCounter $360^{\circ}$, a qual destaca automaticamente os sete vocábulos mais utilizados. A fim de refinar os resultados, descartamos manualmente termos que não pertenciam à classe gramatical dos substantivos. $\mathrm{O}$ resultado se apresenta na Tabela 2.

Tabela 2 - Incidência dos conceitos-chave no corpus.

\begin{tabular}{lr|lr|lc|ll}
\hline \multicolumn{4}{c}{ Record } & \multicolumn{4}{c}{ Globo } \\
Hoje em Dia (2014) & \multicolumn{2}{l}{ Hoje em Dia (2015) } & \multicolumn{2}{c}{ Encontro (2014) } & \multicolumn{2}{c}{ Bem Estar (2015) } \\
\hline Maconha & 35 & Convulsões & 11 & Canabidiol & 13 & Canabidiol & 8 \\
Canabidiol & 24 & Remédio & 11 & Substância & 10 & Remédio & 6 \\
Medicamento & 22 & Canabidiol & 9 & Crises & 10 & Epilepsia & 5 \\
Justiça & 21 & Medicamento & 8 & Maconha & 9 & Crises & 5 \\
Vida & 17 & Liminar & 7 & Medicamento & 8 & Anvisa & 4 \\
Saúde & 17 & Tratamento & 5 & Brasil & 8 & Conselho & 3 \\
Planta & 16 & Estado & 4 & Família & 6 & Medicina & 3 \\
\hline
\end{tabular}

Fonte: Dados da pesquisa.

Com base na Tabela 2, destacam-se os seguintes dados sobre a ressignificação: (1) O termo Canabidiol é um conceitochave antes e depois da liberação da importação pela Anvisa, que aparece como principal vocábulo nos programas da Globo, mas no programa da Record ocupa a segunda posição em 2014 e a terceira em 2015; (2) a palavra "maconha" só aparece como conceito-chave antes da liberação, tanto na Record quanto na Globo, uma hipótese poderia ser construída no sentido de que o processo de alcançar o público passa, primeiro, pela vinculação do canabidiol a maconha e, em seguida, a sua desvinculação. Se num primeiro momento é fundamental para o processo de mediação explicitar que o canabidiol é derivado da maconha, em seguida essa informação perde importância, e os aspectos medicinais ganham preponderância relativa.; (3) os vocábulos que fazem menção ao canabidiol ocupam lugar de destaque entre os conceitos-chave, se repetindo em ambas as emissoras como é o caso de "medicamento" e "remédio", por outro lado, a incidência do termo "substância" só se faz significativa na Globo, enquanto "tratamento" se destaca na Record; e (4) os personagens (Motta, 2013) em destaque são a Justiça e o Estado na Record, enquanto a Globo enfatiza a Família, a Anvisa e o Conselho Federal de Medicina.

O termo canabidiol, assunto principal dos programas analisados, recebeu destaque em todos os programas. Destacouse trechos das matérias que explicam ou definem o que é esse composto para verificar o processo de ressignificação da substância. Os trechos são observados a seguir: 
O canabidiol é uma substância proibida, simplesmente por ser uma substância derivada da maconha. (Encontro, 14 de abril de 2014).

O Canabidiol é um dos 80 princípios ativos presentes na maconha (Hoje em Dia, 13 de outubro de 2014).

O canabidiol é uma das 60 substâncias da planta Cannabis sativa, que tem ação sobre o cérebro. Dessas 60, as duas principais são o Canabidiol (CBD) e o THC. O THC pode desencadear uma esquizofrenia. O Canabidiol pode tratar surto psicótico e controlar as crises de epilepsia [...] (Bem Estar, 15 de janeiro de 2015).

Os três trechos acima foram retirados da fala de profissionais da saúde, entretanto, é possível observar que existem distinções nas definições. No primeiro excerto, o Canabidiol é tido como substância derivada da maconha sem mais explicações. No segundo, já se traz como informação nova o fato do CBD ser um princípio ativo. Mas a maior mudança no discurso ocorre quando é liberada a importação, quando o nome popular é substituído por "planta Cannabis sativa", mostrando uma tentativa de desvencilhar o CBD do imaginário negativo do termo maconha que remete a criminalização do cultivo, venda e uso recreativo.

Em relação às fontes utilizadas para dar credibilidade ao assunto tratado, assim como exemplificar casos do uso do canabidiol, as matérias contaram com a participação e colaboração de famílias e profissionais das áreas de saúde e direito, conforme descrito no Quadro 1. Contudo, é possível observar que algumas matérias não constaram no quadro. Isso se deve ao fato destas somente terem tido a voz dos apresentadores ou repórteres, sem a participação direta dos entrevistados.

Quadro 1 - Fontes entrevistadas em 2014 e 2015.

\begin{tabular}{|c|c|c|c|}
\hline Programa & Data & Fonte & Profissão/Descrição \\
\hline \multirow{3}{*}{ Encontro } & $01 / 04 / 2014$ & Fernando Gomes Pinto & $\begin{array}{l}\text { Médico e pesquisador em } \\
\text { Neurocirurgia e } \\
\text { Neurotraumatologia }\end{array}$ \\
\hline & \multirow{2}{*}{$07 / 04 / 2014$} & Katiele Fischer & Mãe de paciente \\
\hline & & Norberto Fischer & Pai de paciente \\
\hline \multirow{5}{*}{ Hoje em Dia } & \multirow{5}{*}{$02 / 09 / 2014$} & Juliana de Paonello Novaes & Mãe de paciente \\
\hline & & Renato Malcher-Lopes & Pesquisador neurocientista \\
\hline & & $\begin{array}{l}\text { Josiane Aparecida } \\
\text { Marcolino Alves }\end{array}$ & Mãe de paciente \\
\hline & & Nelson Parise & Advogado a OAB - SP \\
\hline & & Júlio Américo Pinto Neto & Pai de paciente \\
\hline \multirow{2}{*}{ Bem Estar } & \multirow{2}{*}{$15 / 01 / 2015$} & Ayla Carla Martins Muniz & Mãe de paciente \\
\hline & & Mauro Aranha de Lima & Vice-presidente do CREMESP \\
\hline \multirow{2}{*}{ Hoje em Dia } & \multirow{2}{*}{$16 / 10 / 2015$} & Alessandra Sato & Mãe de paciente \\
\hline & & Leandro Sato & Pai de paciente \\
\hline
\end{tabular}

Fonte: Dados da Pesquisa.

Observa-se também que dependendo da posição de fala, a fonte traz um discurso diferenciado, porém padronizado, sobre o CBD. As famílias, por possuírem um conhecimento tácito e adquirido por meio do uso do composto, sempre exploram uma mensagem de melhoria da qualidade de vida com o tratamento utilizando o canabidiol.

Katiele Fischer: Fátima... o Canabidiol não vai trazer a cura pra Anny. Porque a síndrome dela não tem cura. Mas vai trazer uma qualidade de vida, que é o que importa (Encontro, 7 abr. 2014 - Grifo nosso).

Ayla Carla Martins Muniz: [O canabidiol] Deu qualidade de vida pra minha filha. Aliviou... a gente hoje pode dormir tranquilo, sem ter medo de acordar com a Manu convulsionando (Bem Estar, 15 jan. 2015 - Grifo nosso).

A escolha por trazer os pais e mostrar as crianças e adolescentes que precisam de tratamento sensibiliza, principalmente quando essas mães e pais garantem que observaram melhora na qualidade de vida. Leva o telespectador a se 
emocionar e gera um sentimento de cumplicidade com aquelas famílias. Por outro lado, pesquisadores e médicos buscam sempre trazer a versão científica dos efeitos e funções desta substância. No trecho abaixo, o neurocientista Renato MalcherLopes fala ao Hoje em Dia qual a função do canabidiol e como ele age no organismo de forma tão complexa, que pode ser difícil para o público compreender tantos termos científicos:

Renato Malcher-Lopes: Ele é importante porque a maneira que o canabidiol age sob um sistema que o nosso organismo tem que é um sistema que é imitado por componentes da maconha, que chama sistema endocanabinoide. A maconha produz substâncias que são chamadas canabinoides. Quando vem da planta, eles chamam fitocanabinoides. No final da década de 80 e início da década de 90 , foi descoberto que o nosso cérebro produz substâncias que atuam da mesma forma, só que de forma específica e mais regulada pelo próprio organismo, que os componentes da planta. Esse sistema é um sistema muito importante, porque ele tem uma característica única que ele coordena todos os aspectos da saúde do indivíduo. Ele inibe a dor, inibe a inflamação, ele evita o excesso de atividade neuronal, o excesso de atividade neuronal pode causar convulsão, como pode causar também ruídos e confusão mental, como é o caso do autismo; ele é anti-inflamatório [pausa] então é um alvo medicinal único, certo? E ele alvo medicinal único não é conhecido agora. Existe um caso que foi relatado em 1843, idêntico ao dessas crianças, onde usaram o óleo de uma variedade que tem muito canabidiol que chama Cannabis Indica, e em 40 dias... no caso da Katiele e da Anny Fischer, em 45 dias ela começou a não ter convulsão. Provavelmente é a mesma doença e em 1843 já se sabia que o óleo de Cannabis Indica podia salvar a vida dessa criança. No caso, quando eu li esse artigo eu fiquei arrepiado (Hoje em Dia, 2 set. 2014).

Em poucos segundos, o pesquisador trouxe uma explicação técnica do que seria o sistema endocanabinoide, no qual o CBD atua, e seu efeito no organismo, além de citar que existem pesquisas desde 1843 do uso do óleo de Cannabis para tratamento de epilepsia. Tanto os cientistas quanto as famílias buscam demonstrar os benefícios do CBD, entretanto, talvez as famílias e os cientistas estivessem tentando atingir públicos distintos devido à linguagem utilizada e a abordagem mais emotiva no primeiro caso ou didática no segundo.

Em relação ao processo de liberação e reclassificação, podemos acrescentar a Justiça representada por Alexandre Crippa (Médico que assinou o laudo de Anny Fischer na liminar) e o Estado, como governo federal. A Anvisa chegou a ser entrevistada, mas é citada de forma indireta, o mesmo ocorreu com o Conselho Federal de Medicina, nenhum dos dois teve um representante presente nas matérias, como exemplifica o trecho a seguir:

Apresentador (Cris Flores): então... a Anvisa informou que analisa essa de reclassificação, que sairia da lista de substâncias proibidas para lista de substâncias controladas. Acho que já ajuda bastante o caso. E que garante a liberação desse medicamento em caráter excepcional, desde que devidamente prescritos por médicos, e também em nota o Conselho Federal de Medicina informou que defende a pesquisa com quaisquer substâncias, mas alertou a população que não confunda o uso de substâncias medicinais da maconha, com produto in natura (Hoje em Dia, 2 set. 2014).

Nesse trecho é possível inferir que a reclassificação veio mediante a demanda das famílias pelo Canabidiol, entretanto, não era interesse desses órgãos a liberação da maconha para os diversos fins. Em relação à participação do público, é possível afirmar que ambas as emissoras exploraram esse recurso, entretanto o fizeram de formas distintas. Na Globo, essa interação ocorre por meio de comentários dos internautas no Encontro, e de perguntar aos especialistas no Bem Estar. Essas perguntas do segundo programa podem ser feitas pela internet ou pelos microfones dos repórteres na rua. 
Figura 2 - Participação do público nos programas da Globo. À esquerda participação no Encontro em 7 de abril de 2014 e no Bem Estar em 14 de dezembro de 2016.

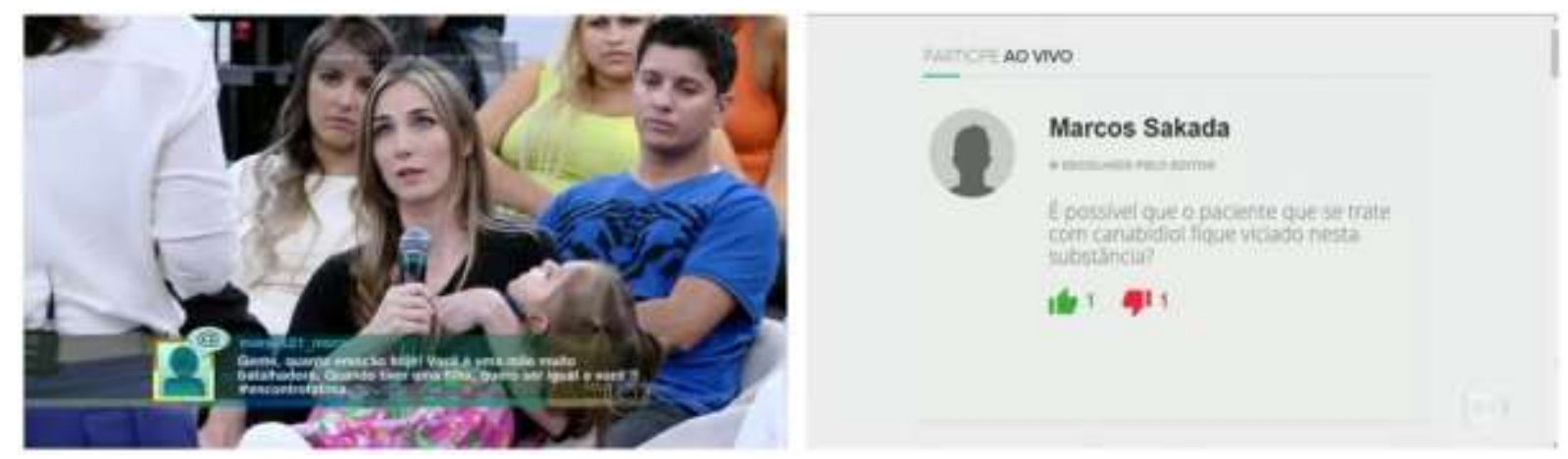

Fonte: Globoplay.

Na Figura 2, é possível observar duas formas de interação do público. Primeiramente, o programa apresentado por Fátima Bernardes já é mais propenso a participação, visto que tem um formato de programa de auditório, o que permite que o público presente fisicamente no estúdio interaja com a apresentadora e os demais participantes. Mas no caso da participação dos internautas, essa ocorre por meio da tag \#encontrofatima. Essas postagens nas redes sociais são coletadas pela produção do programa que projeta os comentários ao vivo na parte inferior da tela. Sabe-se que existe um filtro que escolhe essas mensagens, mas a aparição de algumas já cria uma atmosfera de proximidade com o telespectador, refletindo suas opiniões e emoções. Na figura acima, a telespectadora escreve: “Gente, quanta emoção hoje! Você é uma mãe muito batalhadora. Quando tiver uma filha, quero ser igual a você". A mensagem apareceu propositalmente enquanto Katiele Fischer descrevia sua luta pela importação.

A segunda foto mostra a pergunta de um telespectador que foi selecionada pelo editor para ser transmitida no momento de participação ao vivo do Bem Estar. Marcus Sakada pergunta: “é possível que o paciente que se trate com o canabidiol fique viciado na substância?”. Essa pergunta é respondida ao vivo pelo Médico Neurologista Tarso Adonai da seguinte forma:

Dr. Tarso Adonai: Olha, enfim, o canabidiol é diferente do princípio THC. O THC é o que a gente chama de substância psicoativa. É aquela substância que uma vez utilizada, dá o que a gente popularmente chama de barato. É o que deixa a pessoa eufórica, o que deixa a pessoa gargalhando à toa, o que deixa a pessoa depois... que abre o apetite da pessoa, esse é o efeito do THC. O canabidiol não tem esse efeito que a gente chama de psicotrópico. Ele não tem esse efeito euforizante do barato. A dependência, ela tá relacionada... o vício tá relacionado muito mais ao muito mais ao THC do que ao canabidiol. Por isso que quando você compra algum medicamento cuja preparação seja exclusivamente de canabidiol, o risco de dependência, de vício, é quase nulo. Enquanto o THC sim tem esse efeito bastante conhecido (Bem Estar, 14 dez. 2016).

O Hoje em Dia, por sua vez, realizou uma enquete onde os telespectadores poderiam votar pela internet. Essa enquete ficou aberta durante toda a duração da reportagem (aproximadamente 30 minutos), sendo apresentando o resultado ao final, conforme se observa na Figura 3. 
Figura 3 - Enquete do programa Hoje em Dia no dia 2 de setembro de 2014.
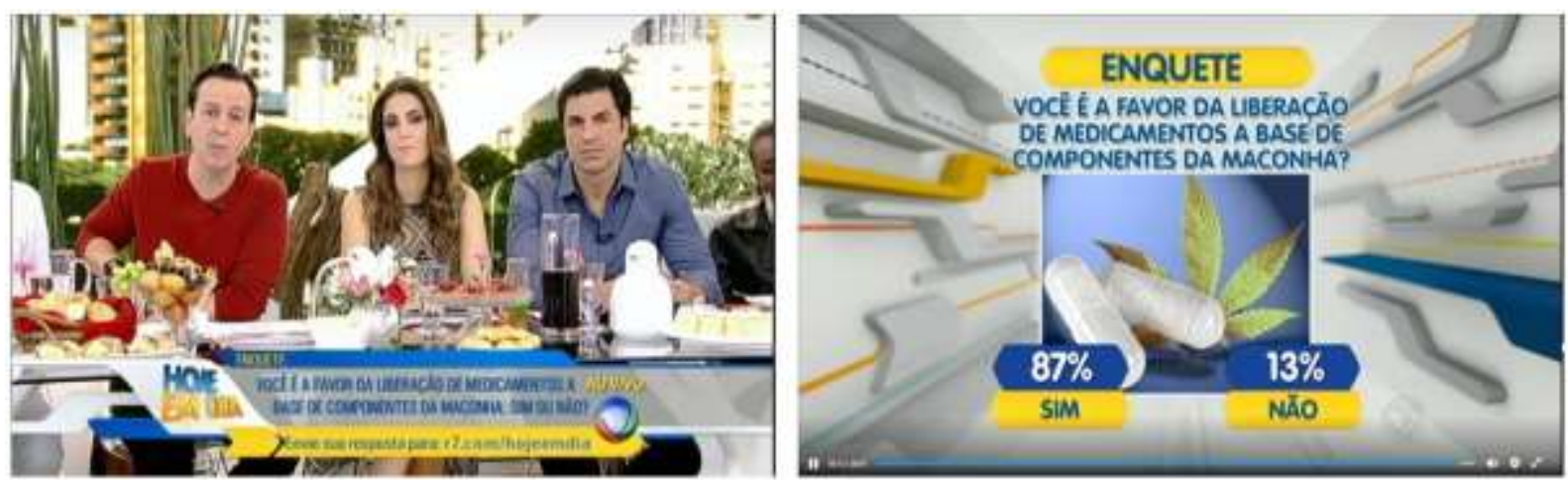

Fonte: R7.

A enquete limita a subjetividade da participação do público, pois reflete em dados numéricos a consulta pública.

Antes de iniciar a enquete, porém os apresentadores tentam deixar claro a posição do programa, assim como da emissora, de serem contra a liberação da maconha, mas estarem debatendo o uso medicinal do canabidiol:

Apresentador (Celso Zucatelli): Nós vamos falar de um outro assunto agora, que também é muito importante, que fala um pouquinho de preconceito. Fala sobre isso sim por conta da falta de informação. Se você tem acompanhado nos últimos dias os avanços da justiça envolvendo a liberação da compra de medicamentos à base de componentes da maconha e a gente tem que explicar direitinho o que é isso. Os nossos convidados estão aqui para falar sobre esse assunto. Antes da gente começar a conversa com eles, coloca a enquete no vídeo pra você. Tá aí, ó: você é a favor da liberação de medicamentos à base de componentes da maconha: sim ou não? Entra lá no r7.com, entra lá r7.com/hojeemdia e dê a sua opinião. Eu vou lhe fazer um convite dessa vez, antes de você dar sua opinião, ouça nossa conversa aqui com eles. Ouça a reportagem, a gente vai conversar sobre isso, pra depois você poder tirar as suas conclusões, certo? (Hoje em Dia, 2 set. 2014).

Ao final, ao divulgar o resultado da enquete, a apresentadora Cris Flores faz um resumo da mesa redonda que foi montada no programa com os convidados e apresentadores, deixando claro que ninguém tem intenção de agir de forma ilegal.

Apresentadora (Cris Flores): [...] Por que o que a gente viu aqui? Você que tá chegando aqui agora... a gente tá vendo dois pais, uma mãe e um pai, que tão lutando pela vida do filho, que é o que há de mais legítimo nesse mundo. E eles seriam capazes sim de dar a própria vida por eles e só o que eles querem é um medicamento que tem um componente que vem da maconha, da planta. Ninguém aqui tá querendo traficar, ninguém tá querendo contrabandear, ninguém aqui tá querendo virar bandido. As pessoas querem assegurar o direito que está na constituição de poder ter saúde, de dar saúde para o seu próprio filho. A gente viu que o pesquisador Renato falou muito bem, com propriedade, que existem pesquisas que comprovam que esse medicamento é eficaz. A gente ouviu o advogado, dizendo sim, vamos importar esse remédio, temos que fazer isso. E a gente fez uma enquete pra ouvir a sua opinião, vamos colocar na tela o resultado da enquete. (Hoje em Dia, 2 set. 2014)

Nesses trechos é possível observar o cuidado dos apresentadores em tratar o tema, demonstrando que o único objetivo é a informação, que, conforme Cris Flores, foi apresentada pelos pais e pelo pesquisador Renato. Após esse trecho, a apresentadora coloca o resultado da enquete, onde $87 \%$ dos participantes votaram que sim, ou seja, são a favor da liberação de medicamentos à base de componentes da maconha. Por fim, o outro apresentador Celso Zucatelli conclui afirmando que é "[...] bom que as pessoas prestaram atenção. Por isso que a gente fez esse convite, pra que você ouvisse essa discussão aqui. Pra gente entender e quebrar os preconceitos. Ninguém tá falando de liberação da droga não. A gente tá falando de medicação" (Hoje em Dia, 2 set. 2014). Esses excertos podem confirmar a hipótese de que o afastamento do tema das matérias do programa da Record após 2015 estejam atrelados ao que sugere Oliveira (2016), pois não é interesse da emissora tratar de um debate sobre os demais usos da maconha, senão o medicinal. 


\section{Considerações Finais}

A análise dos vídeos nos permite observar vários aspectos da liberação do uso medicinal e controlado do canabidiol ao longo do tempo. A ressignificação pode ser observada principalmente por duas estratégias: a argumentatividade e a seleção lexical. A argumentatividade está relacionada com a credibilidade e a legitimação da mídia ao trazer como fonte as famílias dos doentes e os cientistas e médicos especializados em neurociência para tratar tanto da melhoria da qualidade de vida dos pacientes, quanto dos efeitos do uso da substância. Dentro da seleção lexical, é possível observar a intenção de se desvencilhar o canabidiol de uma droga ilícita, isso é observado nas vezes quando este é denominado como remédio, medicamento, medicação ou tratamento, mesmo quando outros medicamentos também são tratados popularmente como drogas.

A reclassificação do Canabidiol, no entanto, não encerrou o debate sobre o tema. Sabe-se que essa discussão permanece viva na Anvisa e no Senado, por meio de consultas públicas e assembleias. As famílias permanecem se mobilizando em associações, por meio das redes sociais, principalmente. Entretanto, o assunto não recebe mais tanta cobertura midiática, devido ao conflito de interesse entre as mobilizações e as redes de televisão. Esporadicamente, o assunto volta a ganhar visibilidade quando há atualização do debate, porém não com tanto destaque como ocorreu entre 2014 e 2016.

Há diferenças na abordagem do tema pelas emissoras, assim como é possível ver que elas criam reportagens e entrevistas muito parecidas, deixando clara a concorrência não só pela audiência como também pela produção de conteúdo e informatividade. São matérias quentes divulgadas simultaneamente ou entrevistas ao vivo com pais e profissionais, com a participação do público. Entretanto, somente a Record se posiciona contra a legalização de drogas, deixando de abordar o tema após 2015. Como resposta, a Globo prepara um especial completo sobre o canabidiol no programa Bem Estar em 2016, que retoma toda a discussão tendo a participação de pais e profissionais da saúde.

Por fim, destaca-se a importância da expertise leiga desenvolvida pelas famílias, pois foi a experiência e troca de informações entre os pais que mobilizou a reclassificação do Canabidiol e, consequentemente, a mediação midiática permitiu ressignificar culturalmente o uso medicinal dos compostos derivados da maconha, conforme os resultados da enquete do Hoje em Dia e os resultados do relatório de Strategos (2016).

Este estudo se dedicou a fazer a análise de um recorte temporal e de um pequeno grupo de programas televisivos. Para compreender todo o debate que se constrói acerca dos usos medicinais da cannabis e seus derivados, faz-se necessário aprofundar em outros programas que abordaram o tema, em um período mais longo. Além disso, a discussão segue ganhando força, tanto na mídia, quanto em setores políticos como o Senado e a Câmara dos Deputados, assim como setores específicos como a Anvisa e o Conselho Federal de Medicina. Deste modo, para estudos futuros, sugerimos que sejam feitas análises desses outros aspectos da discussão, a fim se obter um olhar mais abrangente sobre a ressignificação que essa planta e seus compostos vêm sofrendo diante da opinião pública da sociedade brasileira.

\section{Agradecimentos}

O presente trabalho foi realizado com apoio da Coordenação de Aperfeiçoamento de Pessoal de Nível Superior Brasil (CAPES) - Código de Financiamento 001.

\section{Referências}

Barbosa, M., Barros, É., Lima, G., Silva, G., \& Souza, P. (2020). O uso do composto de Canabidiol no tratamento da doença de Alzheimer(revisão da literatura). Research, Society and Development, 9(8), 1-18. doi:http://dx.doi.org/10.33448/rsd-v9i8.6073

Bardin, L. (2016). Análise de Conteúdo. (L. Reto, \& A. Pinheiro, Trads.) Edições 70.

Bastos, M. T. (2012). Medium, media, mediação e midiatização: a perspectiva germânica. Em M. Â. Mattos, Mediação \& Midiatização (pp. 53-77). Salvador: Edufba - Compós. 
Research, Society and Development, v. 10, n. 2, e16910212344, 2021

(CC BY 4.0) | ISSN 2525-3409 | DOI: http://dx.doi.org/10.33448/rsd-v10i2.12344

Carlini, E. A., Karniol, I. G., Renault, P. F., \& Schuster, C. R. (1974). Effects of marihuana in laboratory-animals and in man. British Journal Of Pharmacology, 50(2), 299-309.

Carvalho, M., Anastácio, C. A., Melo, B., Dias, B., Sousa, F., Moura, H., Freitas, Y. (2020). Projeto de cannabis terapêutica como extensão durante a pandemia: um relato de experiência. Research, Society and Development, 9(12), 1-14. http://dx.doi.org/10.33448/rsd-v9i12.10906

Carvalho, V., Massarani, L., Amorim, L., Ramalho, M., Neves, R. \& Malcher, M. (2015). Ciência na TV aberta brasileira: um perfil da programação diária da Rede Globo e Rede Record. Intercom - Sociedade Brasileira de Estudos Interdisciplinares da Comunicação XXXVIII Congresso Brasileiro de Ciências da Comunicação, (pp. 1-15).

Empresa Jr. de Consultoria Pública Strategos. (2016). Pesquisa sobre percepção dos parlamentares brasileiros sobre política de drogas. http://pbpd.org.br/publicacao/pesquisa-sobre-percepcao-dos-parlamentares-brasileiros-sobre-politica-de-drogas/

Garcia, T., Cruz, M., Silva, G., Cardoso, E., \& Arruda, J. (2020). Canabidiol para o tratamento de pacientes com Síndrome de West e epilepsia. Research, Society and Development, 9(9), 1-17. doi:http://dx.doi.org/10.33448/rsd-v9i9.7267

Instituto Igarapé. (2019). Monitor de Políticas de Drogas nas Américas. https://politicadedrogas.igarape.org.br/

Motta, L. G. (2013). Análise Crítica da Narrativa. Brasília: UNB.

Oliveira, M. B. (2016). O Medicamento Proibido: Como um derivado da maconha foi regulamentado no Brasil. Dissertação (Mestrado), Unicamp, Mestrado em Divulgação Científica e Cultural, Campinas.

Pereira, A., Shitsuka, D., Parreira, F. \& Shitsuka, R. (2018). Metodologia da pesquisa científica. UAB/NTE/UFSM.

Rodrigues, A., Mourão, V., \&. Lopes, I (2020). "Eficácia, segurança e qualidade": parâmetros discursivos nas audiências públicas da Anvisa sobre regulamentação e pesquisas com cannabis para fins medicinais. Teoria e Cultura, 15(2), 134-147. https://doi.org/10.34019/2318-101X.2020.v15.29313

R7. (2019). Hoje em dia. https://recordtv.r7.com/hoje-em-dia.

Serrano, M. M. (1993). La mediación de los medios de comunicación . Em M. Moragas, Sociología de la comunicación de masas. I, 141-162. México, Gili.: Escuelas y autores.

Silva, G., Reis, G., Lopes, K., Rebelo, L., Alencar, S., Serra, V., \& Lopes, G. (2020). Enfermagem: um estudo da fisiopatologia do Alzheimere os seus tratamentos alternativos com células-tronco e cannabis. Research, Society and Developmen, 9(11), 1-20. http://dx.doi.org/10.33448/rsd-v9i11.10094

Stürmer, A. (2014). O tom como marca distintiva do Encontro com Fátima Bernardes. Intercom - Sociedade Brasileira de Estudos Interdisciplinares da Comunicação, (pp. 1-15). Foz do Iguaçu, PR,. 